\title{
A Calcium Paradox in the Context of Neurotransmission
}

\author{
Leandro B. Bergantin ${ }^{1}$, Aron Jurkiewicz ${ }^{1}$, Antonio G. García ${ }^{2}$ and Afonso Caricati-Neto ${ }^{1}$ \\ 1. Department of Pharmacology, Escola Paulista de Medicina, Universidade Federal de São Paulo, São Paulo 04039-032, Brazil \\ 2. Department of Pharmacology, Instituto Teófilo Hernando de I+D del Medicamento, Universidad Autónoma de Madrid, Madrid \\ 28029, Spain
}

\begin{abstract}
The hypothesis of the calcium paradox has its origin in experiments done in neurogenically stimulated rat and mouse vas deferentia. Some old studies reported that reduction of $\mathrm{Ca}^{2+}$ entry by mild concentrations of verapamil, diltiazem or nifedipine elicited the surprising augmentation of vas deferens contractions. Recent reports have also found that nifedipine caused a paradoxical augmentation of the exocytotic release of catecholamine elicited by paired depolarising pulses in voltage-clamped bovine chromaffin cells. Because these drugs are blocking the L-subtype of VACCs (voltage-activated calcium channels), augmented contraction and exocytosis was an unexpected outcome. Recent experiments in neurogenically-stimulated rat vas deferens have found a more drastic potentiation of contractions with the association of verapamil and cAMP-enhancer compounds. Thus, the interaction between the signalling pathways mediated by $\mathrm{Ca}^{2+}$ and cAMP could explain those unexpected findings and the so-called calcium paradox.
\end{abstract}

Key words: Calcium paradox, cAMP, smooth muscle, sympathetic neurotransmission, chromaffin cell.

\section{Introduction}

In mammals, the transient elevations of the concentrations of $\left[\mathrm{Ca}^{2+}\right]_{c}$ (free $\mathrm{Ca}^{2+}$ ions in the cytosol) serve as a messenger signal to couple the stimulus to muscle contraction or to neurosecretion, among other myriad physiological responses [1, 2]. A vast amount of experiments performed since the discovery of the role of $\mathrm{Ca}^{2+}$ in the control of the heart beat [3] have set the dogma that in excitable cells, the enhanced $\mathrm{Ca}^{2+}$ entry through VACCs (voltage-activated $\mathrm{Ca}^{2+}$ channels) elicited by depolarising stimuli, trigger muscle contraction and the release of neurotransmitters and hormones. Conversely, the mitigation of $\mathrm{Ca}^{2+}$ entry produced by blockers of VACCs causes a diminution of those responses [4, 5].

Two observations, however, did not follow the expected outcomes from the concepts of the stimulus-contraction coupling process [6] and the stimulus-secretion coupling [7]. These concepts imply that enhanced $\mathrm{Ca}^{2+}$ entry during cell depolarisation

Corresponding author: Leandro B. Bergantin, Ph.D., research field: autonomic and cardiovascular pharmacology, neurotransmission, cell signaling. E-mail: leanbio39@yahoo.com.br. and/or enhanced $\mathrm{Ca}^{2+}$ release from the SER (sarco-endoplasmic reticulum) augments the $\left[\mathrm{Ca}^{2+}\right]_{\mathrm{c}}$ and the triggering of the contraction or secretion responses. However, near four decades ago verapamil at low concentrations was shown to unexpectedly augment the neurogenically mediated contractions of the rat vas deferens [8]. On the other hand, nifedipine was recently found to paradoxically augment the exocytotic release of catecholamine triggered by double-pulse depolarisations in voltage-clamped bovine adrenal medullary chromaffin cells [9]. How these two blockers of the L-subtype of VACCs can augment, instead of reducing the $\mathrm{Ca}^{2+}$-dependent responses of contraction and secretion? This review is aimed at trying to give a response to this question through the recently coined term of the "calcium paradox" [10].

\section{Paradoxical Effects of $L$ Channel Blockers in the Vas Deferens}

The motor activity of several smooth muscles including lung, gut, blood vessels and vas deferens is controlled by neurotransmitters released from postganglionic sympathetic nerve endings, particularly 
5-ATP (adenosine triphosphate) and NA (noradrenaline). Nerve stimulation with short bursts at low frequency favour ATP releases while longer stimulation periods favour NA release. In both cases, the release process is regulated by several mechanisms including $\mathrm{Ca}^{2+}$ entry through VACCs, augmentation of $\left(\left[\mathrm{Ca}^{2+}\right]_{\mathrm{c}}\right)$, and the increase of intracellular cAMP concentrations $\left([\mathrm{cAMP}]_{\mathrm{i}}\right)[11]$.

In the vas deferens, both release and postsynaptic actions of NA and ATP depend on $\mathrm{Ca}^{2+}$ entry through VACCs and the ensuing elevations of $\left[\mathrm{Ca}^{2+}\right]_{\mathrm{c}}[11]$. Hence, some authors found that verapamil abolished the electrically-evoked neurogenic contractions of the vas deferens [12-13]. In an earlier study, however, it was reported that verapamil blocked the neurogenically mediated contractions of the rat vas deferens, as expected; nevertheless, this study also reported that the lower concentrations of verapamil caused a surprising augmentation of those contractions [8]. This paradoxical effect was corroborated in 1981 by French and Scott [14], also in the electrically stimulated rat vas deferens. Furthermore, six years later a third study reported that verapamil and diltiazem enhanced the purinergic-mediated neurogenic twitch response of the rat vas deferens; this effect was attributed to an agonist effect of verapamil on presynaptic L-type VACCs, thus enhancing $\mathrm{Ca}^{2+}$ entry and ATP release [15]. Two years later a fourth study appeared showing that both, L- type VACC blockers and activator BAY K 8644 elicited similar augmentations of the neurogenic contractions of the mouse vas deferens; the authors did not provide an explanation for such paradoxical observation [16].

In a recent report from our laboratory, we could reproduce those earlier observations in the neurogenically-induced contractions of the rat vas deferens: At lower concentrations verapamil elicited a tiny augmentation, while at higher concentrations the VACC blocker caused full inhibition of the contractions [10]. The interesting finding was that as the high verapamil concentrations, various cAMP enhancers such as phosphodiesterase inhibitors rolipram and IBMX (isobutyl methyl xanthine) and AC (adenylyl cyclase) activator forskolin, depressed the neurogenic vas deferens contractions; however, in the presence of cAMP enhancers the lower concentrations of verapamil caused a drastic augmentation of the neurogenic contractions mediated by endogenously released ATP. The inhibition of AC by SQ 22536 attenuated the enhanced contractions, suggesting that an interaction $\mathrm{Ca}^{2+}$-cAMP could possibly explain the paradoxical effects of combined verapamil plus cAMP enhancers [10]. We will come back to this interaction later on.

\section{Paradoxical Effects of $L$ Channel Blockers in Adrenal Chromaffin Cells}

As in vas deferentia, some paradoxical effects have also been recently reported to occur in adrenal chromaffin cells. For instance, in a study performed in voltage-clamped bovine chromaffin cells, the blockade of $\mathrm{L}$ channels with nifedipine transformed the exocytotic responses elicited by a double-pulse protocol, from depression to facilitation [9]. In an earlier study, it was shown that nifedipine suppressed the endocytotic response triggered by a long depolarising stimulus [17]. The explanation for the paradoxical effect of nifedipine could rest in the fact inhibition of rapid endocytosis triggered by $\mathrm{Ca}^{2+}$ entry through $\mathrm{L}$ channels of bovine chromaffin cells $\left(\alpha_{1 \mathrm{D}}\right.$, Cav 1.3) could unmask a full exocytotic response. A second explanation may lay in the observation that $\mathrm{Ca}^{2+}$ entry through $\mathrm{L}$ channels causes the inhibition of $\mathrm{P} / \mathrm{Q}$ channels $\left(\alpha_{1 \mathrm{~A}}, \mathrm{Cav} 2.1\right)$ [18] that in bovine chromaffin cells greatly contribute to the control of the exocytotic release of catecholamines [19]. By blocking $\mathrm{L}$ channels, nifedipine could remove the $\mathrm{Ca}^{2+}$ dependent inactivation of $\mathrm{P} / \mathrm{Q}$ channels to enhance $\mathrm{Ca}^{2+}$ entry through them, and thereby augmenting exocytosis. An additional explanation for the nifedipine paradoxical effect in chromaffin cells [9] 
could be found in the context of the calcium paradox described in the vas deferens and in the interaction $\mathrm{Ca}^{2+}$-cAMP [10].

In the light of the paradoxical effects of combined verapamil plus rolipram in the vas deferens, it could be possible to implicate cAMP also in the paradoxical effects of nifedipine in the secretory process of chromaffin cells. In fact, several reports have been published on the role of cAMP in the regulation of neurotransmitter release as well as in the postsynaptic actions of different neurotransmitters [11]. Additionally, the release of sympathetic transmitters is regulated both by $\mathrm{Ca}^{2+}$ and cAMP [20-23]. Furthermore, cAMP has also been shown to regulate the release of catecholamine from chromaffin cells. Some studies have shown a correlation between an elevation of $[\mathrm{cAMP}]_{\mathrm{I}}$ and catecholamine release in bovine chromaffin cells stimulated with nicotine [24], PACAP [25], histamine [26] or VIP [27]; this is also true for the PDE inhibitors rolipram or IBMX [28-30].

To enhance secretion, cAMP may act at several targets including the VACCs of chromaffin cells, the regulation of the size of subplasmalemmal vesicle pools and/or the kinetics of the fusion pore during the last steps of exocytosis [28]. Concerning VACCs it is well established that the L-subtypes are the most sensitive to cAMP and PKA (protein kinase A) [31-33]. For example, in mouse chromaffin cells rolipram augments both $[\mathrm{cAMP}]_{\mathrm{I}}, \mathrm{L}$ currents and secretion [34]. Also, rolipram increased the size of the RRP (ready-release-vesicle-pool) [35] by 75\%, nearly doubled the membrane area of single vesicles in rat chromaffin cells [32], and augmented the quantal size by $38 \%$ also in rat chromaffin cells [36]. Furthermore, the AC activator forskolin enhanced by $50 \%$, and rolipram by $25 \%$ the quantal size of single vesicles in bovine chromaffin cells [28]. On the other hand, in mouse chromaffin cells, rolipram increased more the size of the RRP $(47 \%)$ than the quantity of $\mathrm{Ca}^{2+}$ penetrating the cell $(16 \%)$; this suggests that about $30 \%$ of the increased secretion is $\mathrm{Ca}^{2+}$-independent and occurs down-stream of $\left[\mathrm{Ca}^{2+}\right]_{\mathrm{c}}$ elevation through $\mathrm{L}$ channels, most likely by affecting directly the secretory apparatus [34]. However, as in the vas deferens, an interaction between $\mathrm{Ca}^{2+}$ and cAMP may also occur in chromaffin cells; evidence for such interaction is actually lacking. Whether the paradoxical effects of nifedipine could be explained in the context of the calcium paradox emanated from the vas deferens, deserves experimental attention.

\section{Interactions between $\mathrm{Ca}^{2+}$ and cAMP}

The hypothesis for a functional interaction between the intracellular signalling pathways mediated by $\mathrm{Ca}^{2+}$ or cAMP has been extensively studied in a myriad cell and tissue systems. Generally, this interaction results in synergistic effects on cell functions [20, 37-39] and occurs at the level of ACs or PDEs (phosphodiesterases). In general, AC5 and AC6 isoforms are inhibited by a physiological increase of $\left[\mathrm{Ca}^{2+}\right]_{\mathrm{c}}[38,40]$. Recent data suggest that compartmentalization of ACs may also cause functional compartmentalization and $[\mathrm{cAMP}]_{\mathrm{i}}$ oscillations. The more precise and specific compartmentalization takes place with several ACs in proximity to VACCs. Thus, in excitable cells $\mathrm{Ca}^{2+}$-regulated $\mathrm{ACs}$ are modulated by $\mathrm{Ca}^{2+}$ entry through VACCs [41]. Not surprisingly, the form of regulation reported in most studies is that in which ACs are regulated by $\mathrm{Ca}^{2+}$ influx through VACCs.

Calcium also regulates the activity of several PDEs, an issue that nevertheless has been studied to a lesser extent [42]. The specific function of PDEs and their interaction with $\mathrm{Ca}^{2+}$ likely contribute to the generation of cAMP microdomains. This is described in detail in a recent study that examined the response of two PDE1 isoforms to $\mathrm{Ca}^{2+}$ influx through SOCCs (store-operated calcium channels) [43]. Such interaction has also been demonstrated in pancreatic acini [44], parotid acini [20], blowfly salivary glands [23], hepatocytes [21], airway epithelial cells [22], cardiac myocytes [45], skeletal myocytes [46], and 
neurons [47].

The interaction $\mathrm{Ca}^{2+}$-cAMP has been extensively studied at the calcium channels of the ER (endoplasmic reticulum) [48-50]. For example, phosphorylation by PKA increases the open probability of the IP3R1 (inositol-tris-phosphate receptor 1) at submaximal IP3 concentrations in parotid acinar cells [20, 51], suggesting that such phosphorylation increases the affinity of IP3 for its IP3R. In line with this observation are some experiments showing that cAMP augments the IP3R-mediated release of $\mathrm{Ca}^{2+}$ from the ER in AR4-2J cells [52] and in blowfly salivary glands [53]. From a physiological point of view, it is worth mentioning that the activation of cardiac $\beta 1$ adrenergic receptors increases phosphorylation of cardiac RyR2 (ryanodine receptors 2) to enhance $\mathrm{Ca}^{2+}$ release from the SR (sarcoplasmic reticulum), that results in stronger and faster contractions [54]. In addition, a large body of literature discusses the regulation of VACCs in various cell types through their phosphorylation by PKA, including chromaffin cells [55].

Conversely, the cAMP pathway significantly regulates the machinery responsible for the clearance of the $\left[\mathrm{Ca}^{2+}\right] \mathrm{c}$ transients elicited by cell stimulation [56]. Most $\mathrm{Ca}^{2+}$ clearance during cell stimulation and at the end of the stimulation period is mediated by the PMCA (plasma membrane $\mathrm{Ca}^{2+}$ ATPase pump) and the plasmalemmal $\mathrm{NCX}\left(\mathrm{Na}^{+} / \mathrm{Ca}^{2+}\right.$ exchanger $)$ isoforms that are particularly active in cardiac myocytes, neurons and the kidney. The main exchanger isoform is NCX1 that has several splice variants $[56,57]$. Various studies suggested that the cardiac NCX can be phosphorylated by PKA on sites located in the large intracellular loop, which increases its activity [57].

\section{A Calcium Paradox in the Context of Neurotransmission}

We recently re-investigated the paradoxical effects of verapamil on the neurogenic contractions of the rat vas deferens, first reported by Kreye and Luth in 1975 [8]. Considering that drugs which increase cAMP levels classically have relaxant effects in smooth muscles mainly through the inhibition of phosphorylation of smooth muscle myosin, and that high concentrations of L-type VACC blockers inhibit sympathetic transmission, the result we obtained was clearly unexpected: the combination of these drugs produced a drastic potentiation of neurogenic contractions, instead of the expected inhibition (Fig. 1). Based on this intriguing result we built up the "calcium paradox" hypothesis, trying to explain the enigma that existed in sympathetic transmission since 1975 (Figs. 1 and 2).

As discussed above, it is amply documented that cAMP causes the relaxation of smooth muscle; this is also true for L-type VACC blockers. Thus, by using separately compounds that augment cAMP and VACC blockers, their predominant effect could be exerted directly in the smooth muscle (postsynaptic), causing its relaxation. However, at presynaptic level (secretory apparatus, Fig. 2), low concentrations of VACC blockers, as well as agents that produce increase of cAMP may have excitatory effects on neurotransmission and other cellular responses. The combination of these drugs caused a synergistic effect (cAMP and $\mathrm{Ca}^{2+}$ interaction) at this level, so predominating the presynaptic effect, and thus enhancing transmitter release to increase muscle contraction (Fig. 2).

It seems now clear that the "calcium paradox" occurs when using low concentrations of VACC blockers $([8,14-16,58]$. We try to explain this fact in Fig. 2 where two components associated to L-type VACC blockers are shown: the component of channel (fast activity) and the component of signalling pathway (slow activity). At low blocker concentrations, it is plausible that the component of signalling pathways is stronger enough to overcome the effect of mild VACC inhibition. Also, in results from our lab performed in bovine adrenal chromaffin 
A

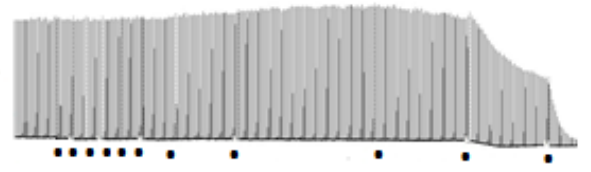

$10^{-9}$
B

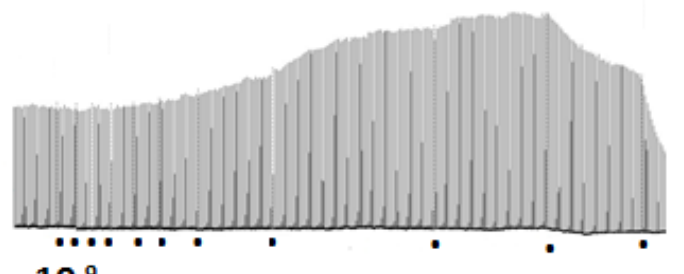

$10^{-9}$
$0.5 \mathrm{~g}$

2 min

Verapamil

Verapamil + Rolipram $10^{-7}$

Fig. 1 Effect of verapamil and rolipram on purinergic neurogenic contractions of the RVD (rat vas deferens) stimulated by electrical field stimulation (EFS $0.05 \mathrm{~Hz}, 50 \mathrm{~V}$ and duration $3 \mathrm{~ms}$ ).
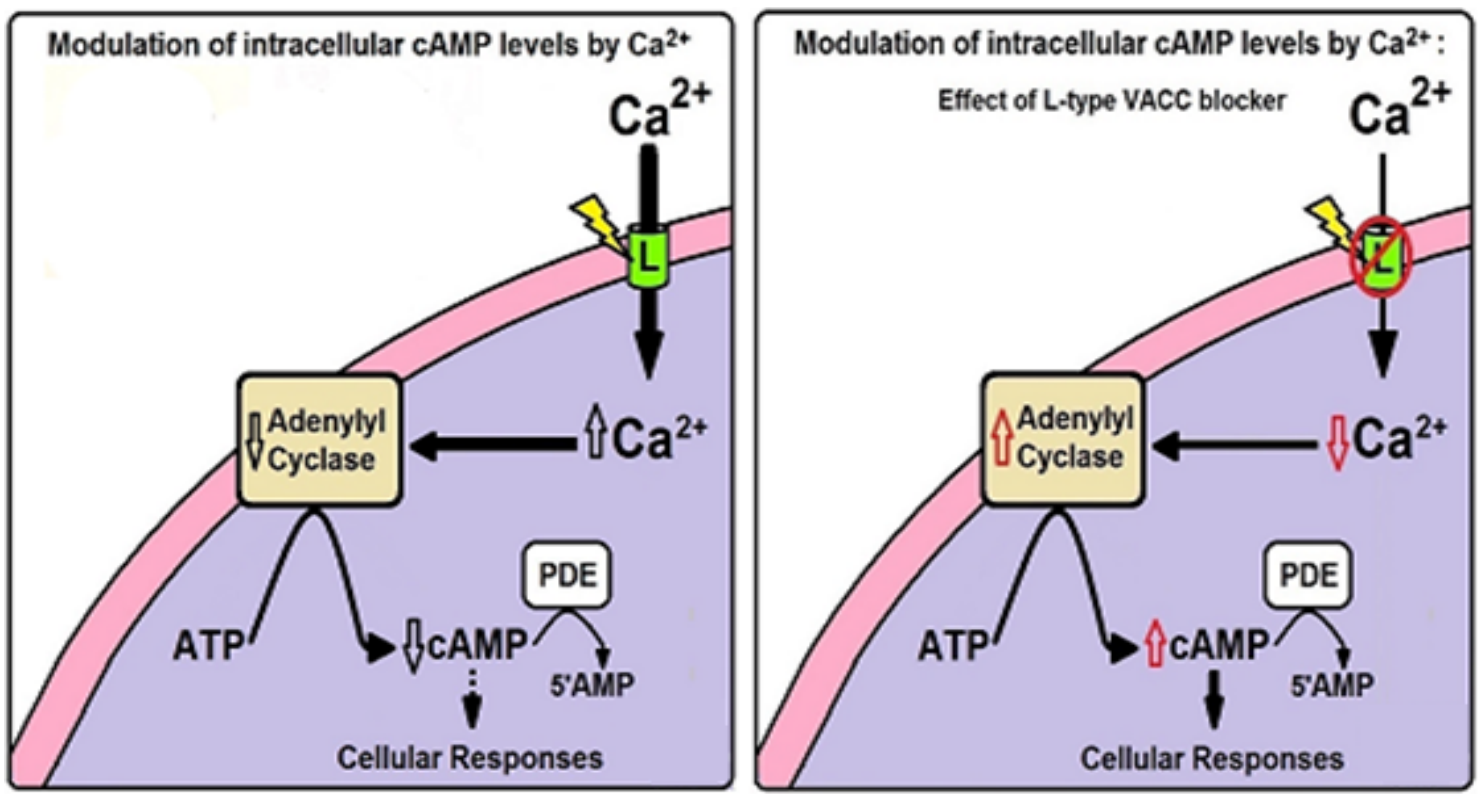

Fig. 2 Schematic representation of the calcium paradox model.

$\mathrm{Ca}^{2+}$ entry through L-type voltage-activated $\mathrm{Ca}^{2+}$ channels (VACCs) modulates $\mathrm{Ca}^{2+}$-sensitive adenylyl cyclases; this intervenes in the regulation of the constitutive cAMP pathway- $\mathrm{Ca}^{2+}$ release from the endoplasmic reticulum. By reducing $\mathrm{Ca}^{2+}$ influx and, consequently $\left[\mathrm{Ca}^{2+}\right]_{\mathrm{c}}$, L-type VACC blockers should reduce secretion. However, the reduction of $\mathrm{Ca}^{2+}$ entry through L VACC blockers verapamil or nifedipine may activate the $\mathrm{Ca}^{2+}$-sensitive adenylyl cyclase, threreby causing the activation of the cAMP pathway $-\mathrm{Ca}^{2+}$ release from the endoplasmic reticulum. Thus, in this model we have two "antagonistic forces" driven by $\mathrm{Ca}^{2+}$ entry and cAMP: the channel component (fast activity) and the component of the signalling pathway (slow activity). The calcium paradox implies a presynaptic reduction of $\mathrm{Ca}^{2+}$ entry produced by the low verapamil concentrations, removal of $\mathrm{Ca}^{2+}$ dependent inhibition of $\mathrm{AC}$ and/or PDE colocalised with L-type VACCs, augmented cAMP, increased ER $\mathrm{Ca}^{2+}$ release via $\mathrm{IP}_{3} \mathrm{Rs}$ and enhanced release of ATP and contraction.

cells (secretory response activity) we clearly see this phenomenon: nifedipine enhances their secretory activity [9]. In addition, it is plausible that the biphasic effect of BAY K 8644 on neurogenic contraction (dose-dependent contraction and relaxation) [59] and secretion [60] could also be explained in the context of the "calcium paradox". At higher concentrations, the intensive influx of $\mathrm{Ca}^{2+}$ promoted by BAY K 8644 may inhibit the constitutive activity of $\mathrm{Ca}^{2+}$ and cAMP signalling pathways associated to L-type VACCs, thus reducing the secretory response mediated by $\mathrm{Ca}^{2+}$ release from the ER (Fig. 2).

The concept of the complex cAMP-IP ${ }_{3} \mathrm{R}$ interaction as a "third messenger", which may mediate the synergistic action of $\mathrm{Ca}^{2+}$ and cAMP signalling, is now emerging [61]. Recent data suggest that IRBIT 
(IP3 receptors binding protein release with IP3) may become central-stage in the mechanism mediating the synergism between cAMP and $\mathrm{Ca}^{2+}$ signalling pathways by functioning as a "third messenger", which favours the crosstalk between $\mathrm{IP}_{3} \mathrm{Rs}$ and other proteins. Another central component is the classical PKA phosphorylation of IP $_{3}$ Rs. For this, IP $_{3}$ Rs, IRBIT, PKA and the effector proteins have to be assembled into microdomains to allow the efficiency of IRBIT. In resting cells when cellular $\mathrm{IP}_{3}$ levels are low, IRBIT is bound to $\mathrm{IP}_{3} \mathrm{Rs}$; thus $\mathrm{IP}_{3} \mathrm{Rs}$ work to buffer the availability of free IRBIT [61]. Increases in cAMP levels may lead to dissociation of IRBIT from $\mathrm{IP}_{3}$ receptors and its translocation to effector proteins located either at intracellular organelles and/or the plasma membrane; in this manner, IRBIT functions as a "third messenger" that transmits the information carried out by the second messengers cAMP and $\mathrm{IP}_{3}$. At the same time, IRBIT integrates and synergizes the activity of the cAMP and $\mathrm{Ca}^{2+}$ signalling systems, providing a molecular mechanism for the synergistic action between them. We think this "idea" fits into the calcium paradox hypothesis; in fact, the release of ER $\mathrm{Ca}^{2+}$ into the cytosol, triggered by verapamil plus rolipram in rat chromaffin cell slices, was blocked upon ER $\mathrm{Ca}^{2+}$ depletion with thapsigargin [10]. Furthermore, considering that this "calcium paradox" could also explain data from different biological systems $[62,63]$, it is becoming apparent that the enigma of "the calcium paradox" in the context of neurotransmission and neurosecretion may be resolved through the interaction between $\mathrm{Ca}^{2+}$ and cAMP. However, further work is needed to clarify this challenging hypothesis.

\section{Potential Therapeutic Translation to the Clinic of the Calcium Paradox}

Considering the model in which $[\mathrm{cAMP}]_{\mathrm{c}}$ stimulates $\mathrm{Ca}^{2+}$ release from SER (Fig. 2), it may be plausible the use of the phosphodiesterase inhibitor rolipram, which increases $[\mathrm{cAMP}]_{\mathrm{i}}[64,65]$, in combination with low doses of verapamil to potentiate neurotransmission for therapeutic purposes. Recently, an animal study suggests that chronic treatment with rolipram together with typical antidepressants may be successful in treating depression [66]. Otherwise, verapamil is extensively used in the clinic, for example, to reduce blood pressure, especially in combination with other drugs for treating angina or cardiac dysrhythmias [67].

We could also infer that a therapy involving the combination of rolipram and verapamil should be done carefully in depressive and hypertensive patients, considering the role of sympathetic transmission in regulating vascular tone by releasing neurotransmitters into the vasculature. Thus, combination of L-type VACC blockers and rolipram, which increases $[\mathrm{cAMP}]_{\mathrm{i}}$, could be used to enhance neurotransmission and mitigate deleterious excess $\mathrm{Ca}^{2+}$ influx, a condition seen in aging and neurodegenerative diseases [68]. These hypotheses need further investigation in experiments with animal models of disease as well as in clinical trials.

Note that neurogenic contractions were decreased at the higher verapamil concentrations (A); however, they were greatly potentiated by combined verapamil plus rolipram (B). (Extracted from Bergantin et al., 2013

Calcium - http://www.sciencedirect.com/science/articl e/pii/S0143416013000894). (In accordance with "author use"-Reuse of portions or extracts from the article in other works). Elsevier Copyright. 2015. "Describes the rights related to the publication and distribution of research." Elsevier. Accessed August 11 , 2015. http://www.elsevier.com/about/company-information/ policies/copyright.

\section{Conclusions}

This review indicates that an interaction between $\mathrm{Ca}^{2+}$ and cAMP signaling pathway could be important in the fine regulation of transmitter release from nerve 
ending, and dysfunctions of this interaction could be involved in adverse effects of anti-hypertensive and anti-depressant drugs. In contrast, this interaction could be a novel strategy to enhance neurotransmission and mitigate deleterious excess $\mathrm{Ca}^{2+}$ influx, a condition seen in aging and neurodegenerative diseases.

\section{Acknowledgments}

Bergantin, Jurkiewicz and Caricati-Neto thank the continued financial support from CAPES, CNPQ and FAPESP (Bergantin's postdoctoral fellowship FAPESP \#2014/10274-3). García thanks financial support from MINECO SAF 2010-21795, CABICYC (Bioibérica-UAM) and Fundación Teófilo Hernando. The authors thank Elsevier-"author use"-Reuse of portions or extracts from the article in other works http://www.elsevier.com/journal-authors/author-rights -and-responsibilities\#author-use.

\section{References}

[1] Berridge, M. J. 2013. "Dysregulation of Neural Calcium Signaling in Alzheimer Disease, Bipolar Disorder and Schizophrenia." Prion 7: 2-13.

[2] Berridge, M. J. 2014. "Calcium Regulation of Neural Rhythms, Memory and Alzheimer's Disease.” J. Physiol. 592: 281-93.

[3] Ringer, S. 1883. "A Third Contribution Regarding the Influence of the Inorganic Constituents of the Blood on the Ventricular Contraction.” J. Physiol. 4: 222-5.

[4] Fleckenstein, A. 1983. "History of Calcium Antagonists." Circ. Res. 52: 13-6.

[5] Garcia, A. G., Garcia-De-Diego, A. M., Gandia, L., Borges, R., and Garcia-Sancho, J. 2006. "Calcium Signaling and Exocytosis in Adrenal Chromaffin Cells." Physiol. Rev. 86: 1093-131.

[6] Sandow, A. 1952. "Excitation-Contraction Coupling in Muscular Response.” Yale J. Biol. Med. 25: 176-201.

[7] Douglas, W. W. 1968. "Stimulus-Secretion Coupling: The Concept and Clues from Chromaffin and Other Cells.” Br. J. Pharmacol. 34: 451-74.

[8] Kreye, V. A., and Luth, J. B. 1975. "Proceedings: Verapamil-Induced Phasic Contractions of the Isolated Rat Vas Deferens." Naunyn Schmiedebergs Arch. Pharmacol. 287 (Suppl): R43.

[9] Rosa, J. M., Conde, M., Nanclares, C., Orozco, A., Colmena, I., de-Pascual, R., Garcia, A. G., and Gandia, L.
2011. "Paradoxical Facilitation of Exocytosis by Inhibition of L-Type Calcium Channels of Bovine Chromaffin Cells.” Biochem. Biophys. Res. Commun. 410: 307-11.

[10] Bergantin, L. B., Souza, C. F., Ferreira, R. M., Smaili, S. S., Jurkiewicz, N. H., Caricati-Neto, A., and Jurkiewicz, A. 2013. "Novel Model for "Calcium Paradox" in Sympathetic Transmission of Smooth Muscles: Role of Cyclic AMP Pathway.” Cell Calcium 54: 202-12.

[11] Burnstock, G. 2009. "Autonomic Neurotransmission: 60 Years since Sir Henry Dale." Annu. Rev. Pharmacol. Toxicol. 49: 1-30.

[12] Hidalgo, A., Beneit, J., and Lorenzo, P. 1983. "Effect of Calcium Antagonists on the Response of the Rat Vas Deferens to Noradrenaline and Field Stimulation." Rev. Esp. Fisiol. 39: 211-5.

[13] Hata, F., Fujita, A., Saeki, K., Kishi, I., Takeuchi, T., and Yagasaki, O. 1992. "Selective Inhibitory Effects of Calcium Channel Antagonists on the Two Components of the Neurogenic Response of Guinea Pig Vas Deferens." J. Pharmacol. Exp. Ther. 263: 214-20.

[14] French, A. M., and Scott, N. C. 1981. "A Comparison of the Effects of Nifedipine and Verapamil on Rat Vas Deferens.” Br. J. Pharmacol. 73: 321-3.

[15] Moritoki, H., Iwamoto, T., Kanaya, J., Maeshiba, Y., Ishida, Y., and Fukuda, H. 1987. "Verapamil Enhances the Non-adrenergic Twitch Response of Rat Vas Deferens.” Eur. J. Pharmacol. 140: 75-83.

[16] Rae, G. A., and Calixto, J. B. 1989. "Interactions of Calcium Antagonists and the Calcium Channel Agonist Bay K 8644 on Neurotransmission of the Mouse Isolated Vas Deferens." Br. J. Pharmacol. 96: 333-40.

[17] Rosa, J. M., de Diego, A. M., Gandia, L., and Garcia, A. G. 2007. "L-type Calcium Channels Are Preferentially Coupled to Endocytosis in Bovine Chromaffin Cells." Biochem. Biophys. Res. Commun. 357: 834-9.

[18] Rosa, J. M., Gandia, L., and Garcia, A. G. 2009. "Inhibition of $\mathrm{N}$ and PQ Calcium Channels by Calcium Entry through L Channels in Chromaffin Cells." Pflugers Arch. 458: 795-807.

[19] Lopez, M. G., Villarroya, M., Lara, B., Martinez Sierra, R., Albillos, A., Garcia, A. G., and Gandia, L. 1994. "Qand L-Type $\mathrm{Ca}^{2+}$ Channels Dominate the Control of Secretion in Bovine Chromaffin Cells.” FEBS Lett. 349: 331-7.

[20] Bruce, J. I., Shuttleworth, T. J., Giovannucci, D. R., and Yule, D. I. 2002. "Phosphorylation of Inositol 1, 4, 5-Trisphosphate Receptors in Parotid Acinar Cells, a Mechanism for the Synergistic Effects of cAMP on $\mathrm{Ca}^{2+}$ Signaling.” J. Biol. Chem. 277: 1340-8.

[21] Chatton, J. Y., Cao, Y., Liu, H., and Stucki, J. W. 1998. "Permissive Role of cAMP in the Oscillatory $\mathrm{Ca}^{2+}$ 
Response to Inositol 1, 4, 5-Trisphosphate in Rat Hepatocytes." Biochem. J. 330 (Pt3): 1411-6.

[22] Lee, R. J., and Foskett, J. K. 2010. "cAMP-Activated $\mathrm{Ca}^{2+}$ Signaling Is Required for CFTR-Mediated Serous Cell Fluid Secretion in Porcine and Human Airways." J. Clin. Invest. 120: 3137-48.

[23] Fechner, L., Baumann, O., and Walz, B. 2013. "Activation of the Cyclic AMP Pathway Promotes Serotonin-Induced $\mathrm{Ca}^{2+}$ Oscillations in Salivary Glands of the Blowfly Calliphora Vicina." Cell Calcium 53: 94-101.

[24] Anderson, K., Robinson, P. J., and Marley, P. D. 1992. "Cholinoceptor Regulation of Cyclic AMP Levels in Bovine Adrenal Medullary Cells.” Br. J. Pharmacol. 106: 360-6.

[25] Przywara, D. A., Guo, X., Angelilli, M. L., Wakade, T. D., and Wakade, A. R. 1996. "A Non-cholinergic Transmitter, Pituitary Adenylate Cyclase-Activating Polypeptide, Utilizes a Novel Mechanism to Evoke Catecholamine Secretion in Rat Adrenal Chromaffin Cells.” J. Biol. Chem. 271: 10545-50.

[26] Marley, P. D. 2003. "Mechanisms in Histamine-Mediated Secretion from Adrenal Chromaffin Cells." Pharmacol. Ther. 98: 1-34.

[27] Wilson, S. P. 1988. "Vasoactive Intestinal Peptide Elevates Cyclic AMP Levels and Potentiates Secretion in Bovine Adrenal Chromaffin Cells." Neuropeptides 11: 17-21.

[28] Machado, J. D., Morales, A., Gomez, J. F., and Borges, R. 2001. "cAMP Modulates Exocytotic Kinetics and Increases Quantal Size in Chromaffin Cells." Mol. Pharmacol. 60: 514-20.

[29] Marley, P. D., and Thomson, K. A. 1992. "Regulation of Cyclic AMP Metabolism in Bovine Adrenal Medullary Cells." Biochem. Pharmacol. 44: 2105-10.

[30] Marley, P. D., Thomson, K. A., Jachno, K., and Johnston, M. J. 1991. "Histamine-Induced Increases in Cyclic AMP Levels in Bovine Adrenal Medullary Cells." Br. J. Pharmacol. 104: 839-46.

[31] Carabelli, V., Hernandez-Guijo, J. M., Baldelli, P., and Carbone, E. 2001. "Direct Autocrine Inhibition and cAMP-Dependent Potentiation of Single L-type $\mathrm{Ca}^{2+}$ Channels in Bovine Chromaffin Cells." J. Physiol. 532: 73-90.

[32] Carabelli, V., Giancippoli, A., Baldelli, P., Carbone, E., and Artalejo, A. R. 2003. "Distinct Potentiation of L-type Currents and Secretion by cAMP in Rat Chromaffin Cells." Biophys. J. 85: 1326-37.

[33] Cesetti, T., Hernandez-Guijo, J. M., Baldelli, P., Carabelli, V., and Carbone, E. 2003. "Opposite Action of Beta 1and Beta 2-Adrenergic Receptors on Ca (V)1 L-Channel Current in Rat Adrenal Chromaffin Cells." J. Neurosci.
23: 73-83.

[34] Marcantoni, A., Carabelli, V., Vandael, D. H., Comunanza, V., and Carbone, E. 2009. "PDE Type-4 Inhibition Increases L-Type $\mathrm{Ca}^{2+}$ Currents, Action Potential Firing, and Quantal Size of Exocytosis in Mouse Chromaffin Cells." Pflugers Arch. 457: 1093-110.

[35] Neher, E. 1998. "Vesicle Pools and $\mathrm{Ca}^{2+}$ Microdomains: New Tools for Understanding Their Roles in Neurotransmitter Release." Neuron 20: 389-99.

[36] Tang, K. S., Tse, A., and Tse, F. W. 2005. "Differential Regulation of Multiple Populations of Granules in Rat Adrenal Chromaffin Cells by Culture Duration and Cyclic AMP.” J. Neurochem. 92: 1126-39.

[37] Cooper, D. M., Mons, N., and Karpen, J. W. 1995. "Adenylyl Cyclases and the Interaction between Calcium and cAMP Signalling." Nature 374: 421-4.

[38] Halls, M. L., and Cooper, D. M. 2011. "Regulation by $\mathrm{Ca}^{2+}$-Signaling Pathways of Adenylyl Cyclases." Cold Spring Harb Perspect Biol. 3: a004143.

[39] Antoni, F. A. 2012. "Interactions between Intracellular Free $\mathrm{Ca}^{2+}$ and Cyclic AMP in Neuroendocrine Cells." Cell Calcium 51: 260-6.

[40] Willoughby, D. 2012. "Organization of cAMP Signalling Microdomains for Optimal Regulation by $\mathrm{Ca}^{2+}$ Entry." Biochem. Soc. Trans. 40: 246-50.

[41] Fagan, K. A., Graf, R. A., Tolman, S., Schaack, J., and Cooper, D. M. 2000. "Regulation of a $\mathrm{Ca}^{2+}$-Sensitive Adenylyl Cyclase in an Excitable Cell. Role of Voltage-Gated Versus Capacitative $\mathrm{Ca}^{2+}$ Entry." J. Biol. Chem. 275: 40187-94.

[42] Bender, A. T., and Beavo, J. A. 2006. "Cyclic Nucleotide Phosphodiesterases: Molecular Regulation to Clinical Use." Pharmacol. Rev. 58: 488-520.

[43] Goraya, T. A., Masada, N., Ciruela, A., Willoughby, D., Clynes, M. A., and Cooper, D. M. 2008. "Kinetic Properties of $\quad \mathrm{Ca}^{2+} /$ Calmodulin-Dependent Phosphodiesterase Isoforms Dictate Intracellular cAMP Dynamics in Response to Elevation of Cytosolic $\mathrm{Ca}^{2+}$." Cell Signal 20: 359-74.

[44] Giovannucci, D. R., Groblewski, G. E., Sneyd, J., and Yule, D. I. 2000. "Targeted Phosphorylation of Inositol 1, 4, 5-Trisphosphate Receptors Selectively Inhibits Localized $\mathrm{Ca}^{2+}$ Release and Shapes Oscillatory $\mathrm{Ca}^{2+}$ Signals.” J. Biol. Chem. 275: 33704-11.

[45] Marks, A. R. 2013. "Calcium Cycling Proteins and Heart Failure: Mechanisms and Therapeutics." J. Clin. Invest. 123: 46-52.

[46] Fuller, M. D., Emrick, M. A., Sadilek, M., Scheuer, T., and Catterall, W. A. 2010. "Molecular Mechanism of Calcium Channel Regulation in the Fight-or-Flight Response." Sci. Signal 3: ra70.

[47] Wang, H., and Zhang, M. 2012. "The Role of 
$\mathrm{Ca}^{2+}$-Stimulated Adenylyl Cyclases in Bidirectional Synaptic Plasticity and Brain Function." Rev. Neurosci. 23: 67-78.

[48] Wagner, L. E. 2nd, Joseph, S. K., and Yule, D. I. 2008. "Regulation of Single Inositol 1, 4, 5-Trisphosphate Receptor Channel Activity by Protein Kinase A Phosphorylation." J. Physiol. 586: 3577-96.

[49] Lanner, J. T., Georgiou, D. K., Joshi, A. D., and Hamilton, S. L. 2010. "Ryanodine Receptors: Structure, Expression, Molecular Details, and Function in Calcium Release." Cold Spring Harb Perspect Biol. 2: a003996.

[50] Yule, D. I., Betzenhauser, M. J., and Joseph, S. K. 2010. "Linking Structure to Function: Recent Lessons from Inositol 1, 4, 5-Trisphosphate Receptor Mutagenesis." Cell Calcium 47: 469-79.

[51] Bruce, J. I., Straub, S. V., and Yule, D. I. 2003. "Crosstalk between cAMP and $\mathrm{Ca}^{2+}$ Signaling in Non-excitable Cells." Cell Calcium 34: 431-44.

[52] Regimbald-Dumas, Y., Arguin, G., Fregeau, M. O., and Guillemette, G. 2007. "cAMP-Dependent Protein Kinase Enhances Inositol 1, 4, 5-Trisphosphate-Induced $\mathrm{Ca}^{2+}$ Release in AR4-2J Cells.” J. Cell Biochem. 101: 609-18.

[53] Schmidt, R., Baumann, O., and Walz, B. 2008. "cAMP Potentiates InsP3-Induced $\mathrm{Ca}^{2+}$ Release from the Endoplasmic Reticulum in Blowfly Salivary Glands." BMC Physiol. 8: 10.

[54] Bers, D. M. 2002. "Cardiac Excitation-Contraction Coupling." Nature 415: 198-205.

[55] Vandael, D. H., Mahapatra, S., Calorio, C., Marcantoni, A., and Carbone, E. 2013. "Cav1.3 and Cav1.2 Channels of Adrenal Chromaffin Cells: Emerging Views on cAMP/cGMP-Mediated Phosphorylation and Role in Pacemaking." Biochim. Biophys. Acta. 1828: 1608-18.

[56] Cerra, M. C., and Imbrogno, S. 2012. "Phospholamban and Cardiac Function: A Comparative Perspective in Vertebrates." Acta. Physiol (Oxf) 205: 9-25.

[57] Zhang, Y. H., and Hancox, J. C. 2009. "Regulation of Cardiac $\mathrm{Na}^{+}-\mathrm{Ca}^{2+}$ Exchanger Activity by Protein Kinase Phosphorylation-Still a Paradox?" Cell Calcium 45: $1-10$.

[58] Pirisino, R., Banchelli, G., Ignesti, G., Mantelli, L., Matucci, R., Raimondi, L., and Buffoni, F. 1993. "Calcium Modulatory Properties of 2,
6-Dibutylbenzylamine (B25) in Rat Isolated Vas Deferens, Cardiac and Smooth Muscle Preparations." $\mathrm{Br}$. J. Pharmacol. 109: 1038-45.

[59] Fontaine, J., and Lebrun, P. 1988. "Pharmacological Analysis of the Effects of Bay K 8644 and Organic Calcium Antagonists on the Mouse Isolated Distal Colon.” Br. J. Pharmacol. 94: 1198-205.

[60] Garcia, A. G., Sala, F., Reig, J. A., Viniegra, S., Frias, J., Fonteriz, R., and Gandia, L. 1984. "Dihydropyridine BAY-K-8644 Activates Chromaffin Cell Calcium Channels." Nature 309: 69-71.

[61] Ahuja, M., Jha, A., Maleth, J., Park, S., and Muallem, S. 2014. "cAMP and $\mathrm{Ca}^{2+}$ Signaling in Secretory Epithelia: Crosstalk and Synergism." Cell Calcium. 55: 385-93.

[62] Nishimura, M., Asai, F., and Urakawa, N. 1982. "Verapamil-Induced Transmitter Release in Rat Diaphragm Muscle.” Jpn. J. Pharmacol. 32: 231-5.

[63] Koshi, T. 1993. “Abnormal Secretory Response to Verapamil of Pancreatic B Cells of Neonatal Rats Maintained in High Glucose." Nihon Naibunpi Gakkai Zasshi 69: 973-88.

[64] Sommer, N., Loschmann, P. A., Northoff, G. H., Weller, M., Steinbrecher, A., Steinbach, J. P., Lichtenfels, R., Meyermann, R., Riethmuller, A., and Fontana, A. 1995. "The Antidepressant Rolipram Suppresses Cytokine Production and Prevents Autoimmune Encephalomyelitis.” Nat. Med. 1: 244-8.

[65] Xiao, L., O'Callaghan, J. P., and O’Donnell, J. M. 2011. "Effects of Repeated Treatment with Phosphodiesterase-4 Inhibitors on cAMP Signaling, Hippocampal Cell Proliferation, and Behavior in the Forced-Swim Test." J. Pharmacol. Exp. Ther. 338: 641-7.

[66] Li, Y. F., Cheng, Y. F., Huang, Y., Conti, M., Wilson, S. P., O'Donnell, J. M., and Zhang, H. T. 2011. "Phosphodiesterase-4D Knock-Out and RNA Interference-Mediated Knock-Down Enhance Memory and Increase Hippocampal Neurogenesis via Increased cAMP Signaling." J. Neurosci 31: 172-83.

[67] Elliott, W. J., and Ram, C. V. 2011. "Calcium Channel Blockers.” J. Clin. Hypertens. (Greenwich) 13: 687-9.

[68] Kawamoto, E. M., Vivar, C., and Camandola, S. 2012. "Physiology and Pathology of Calcium Signaling in the Brain.” Front Pharmacol. 3: 61. 